УДК 66.047

\title{
ОСОБЛИВОСТІ ТЕПЛОВІДДАЧІ ПРИ ВИМУШЕНІЙ КОНВЕКЦІЇ В РОТОРНО-ДИСКОВОМУ ПЛІВКОВОМУ ВИПАРНОМУ АПАРАТІ
}

Ободович О.М. ${ }^{1}$, док. техн. наук, Ружинська Л.І. ${ }^{2}$, канд. техн. наук, Костик С.І. ${ }^{1,2}$, канд. техн. наук, Булах Н.М.²

${ }^{1}$ Інститут технічної теплофізики НАН України, вул. Желябова, 2а, Київ, 03680, Украина

${ }^{2}$ Національний технічний університет Украӥни «Київський політехнічний інститут», просп. Перемоги, 37, корпус 4, Київ, 03056, Украина

Отримані значення коефіцієнтів тепловіддачі від теплоносія (вуглекислий газ) до плівки рідини для діапазону швидкостей $9,3 \ldots 12,5$ м/с в каналі роторно-дискового плівкового випарного апарату.

Запропоноване модифіковане критеріальне рівняння тепловіддачі при вимушеній конвекції для роторно-дискового плівкового випарного апарату, яке може бути використано для підвищення точності інженерних розрахунків параметрів тепловіддачі тепломасообмінного обладнання.

Бібл. 8, рис. 7.
Получены значения коэффициэнтов теплоотдачи от теплоносителя (углекислый газ) к пленке жидкости для диапазона скоростей 9,3...12,5 м/с в канале роторно-дискового пленочного испарительного аппарата.

Предложено модифицированное критериальное уравнения теплоотдачи при вынужденной конвекции для роторно-дискового пленочного выпарного аппарата, которое может быть использовано для повышения точности инженерных расчетов параметров теплоотдачи тепломассообменного оборудова-
Heat emission factors from carbonic acid gas to liquid for gas speed about $9,3 \ldots 12,5 \mathrm{~m} / \mathrm{s}$ in the rotary-disk tape evaporative apparatus canal.

The modified criterion equation of heat transfer in forced convection rotary disc film evaporator, which can be used to improve the accuracy of engineering calculations of heat and mass transfer parameters of heat transfer equipment.

Ключові слова: тепловіддача, вимушена конвекція, роторно-дисковий плівковий випарний апарат, тепломасообмін.

В основу досліджень поставлена задача розрахунку коефіцієнтів критеріальних рівнянь Нуссельта для установки, яка призначена для концентрування термолабільних матеріалів, основним апаратом якої $\epsilon$ роторно-дисковий плівковий випарний апарат (РДПВА), зображений на рис. 1.

Розміщені на валу апарату диски приводяться в обертовий рух за допомогою приводу. Нижня частина дисків, занурена в об'єм розчину, що концентрується, при обертанні захоплює частину рідини (плівку) і виносить іiї в зону контакту 3 теплоносієм. Вважаємо, що в процесі теплообміну вся кількість тепла йде на процес випарювання вологи $з$ плівки, при цьому поверхня диску не нагрівається.

Для здійснення необхідних процесів тепломасообміну газоподібний теплоносій направляється в канали, що утворюються між паралельно розташованими дисками. Теплоносій напрямляється в бік протилежний до обертання дисків, що сприяє інтенсифікації теплообмінних процесів.

Пройшовши зону контакту 3 теплоносієм, диски знову занурюються в об'єм. При цьому зневоднена плівка рідини на диску розчиняється і переходить в робочий об' $є$ м $[1,2]$. Основний процес, що відбувається в даному апараті, - процес теплообміну, а конкретно - тепловіддачі від гарячого теплоносія до плівки рідини.

При розрахунках випарників такого типу виникає необхідність використання критеріальних рівнянь Нуссельта. Для цього існує безліч довідників та рівнянь для кожного 
конкретного випадку. Недоліком цих розрахунків $\epsilon$ емпіричний спосіб отримання рівнянь Нуссельта та їх узагальнюючий характер, оскільки дані рівняння є досить наближеними. Через нагнітання гарячого повітря за допомогою вентилятора в апараті має місце режим вимушеної конвекції.

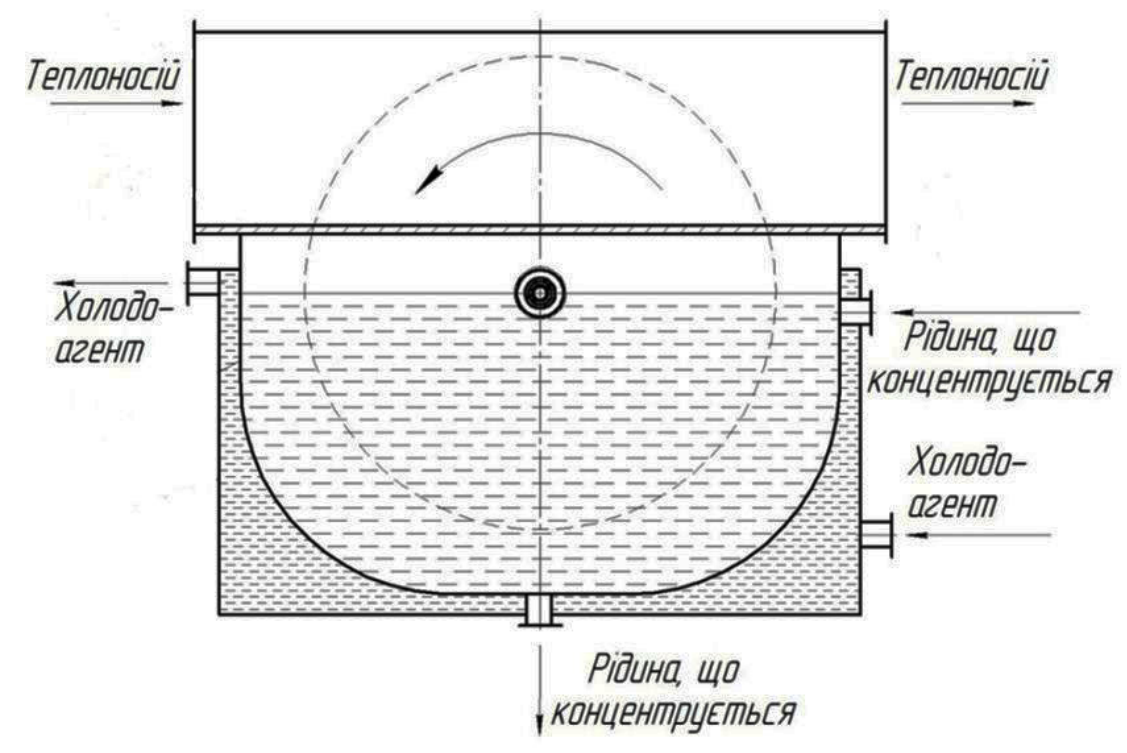

Рис. 1. Схема роторно-дискового плівкового випарного апарата.

Мета дослідження: уточнення коефіцієнтів $C$ і $n$ для режиму вимушеної конвекції в каналі роторно-дискового плівкового випарного апарату.

На реальному РДПВА були проведені дослідження. У якості модельної рідини була обрана вода, у якості теплоносія - двоокис вуглецю. На критерій Нуссельта досить вагомий вплив має число Рейнольдса, яке характеризує режим руху теплоносія в каналі і переважно залежить від його швидкості.

При роботі на експериментальному стенді було встановлено, що швидкість потоку теплоносія, в залежності від положення заслінки $\varphi$, лежить в межах від 9,3 до 12,5 м/с, при цьому об'ємна витрата теплоносія складає від 0,0372 до $0,0484 \mathrm{~m}^{3} / \mathrm{c}$ (рис. 2).

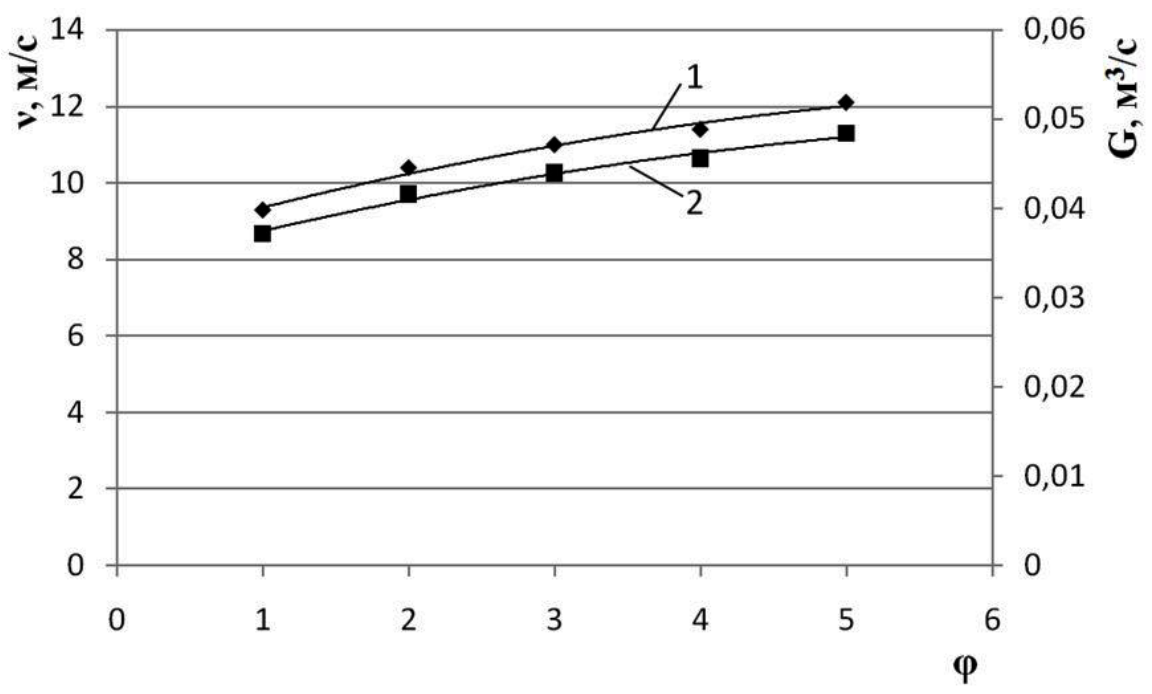

Рис. 2. Характеристики потоку теплоносія: 1- швидкість потоку теплоносія в каналі, м/с; 2 - витрата теплоносія в каналі, $\mathbf{M}^{3} / c$. 
Проведені дослідження на стенді показали, що при температурі теплоносія $80{ }^{\circ} \mathrm{C}$, температура розчину, що концентрується, становить $30 \ldots 35{ }^{\circ} \mathrm{C}$ і швидкості потоку теплоносія $10 \ldots 12 \mathrm{M} / \mathrm{c}$, при площі поверхні тепломасо- обміну 0,22 м², кількість випареної вологи за одиницю часу складає 1150 мл/год (рис. 3), а кількість затраченої теплової енергії на процес випарювання складає 16200 кДж (3869 ккал).

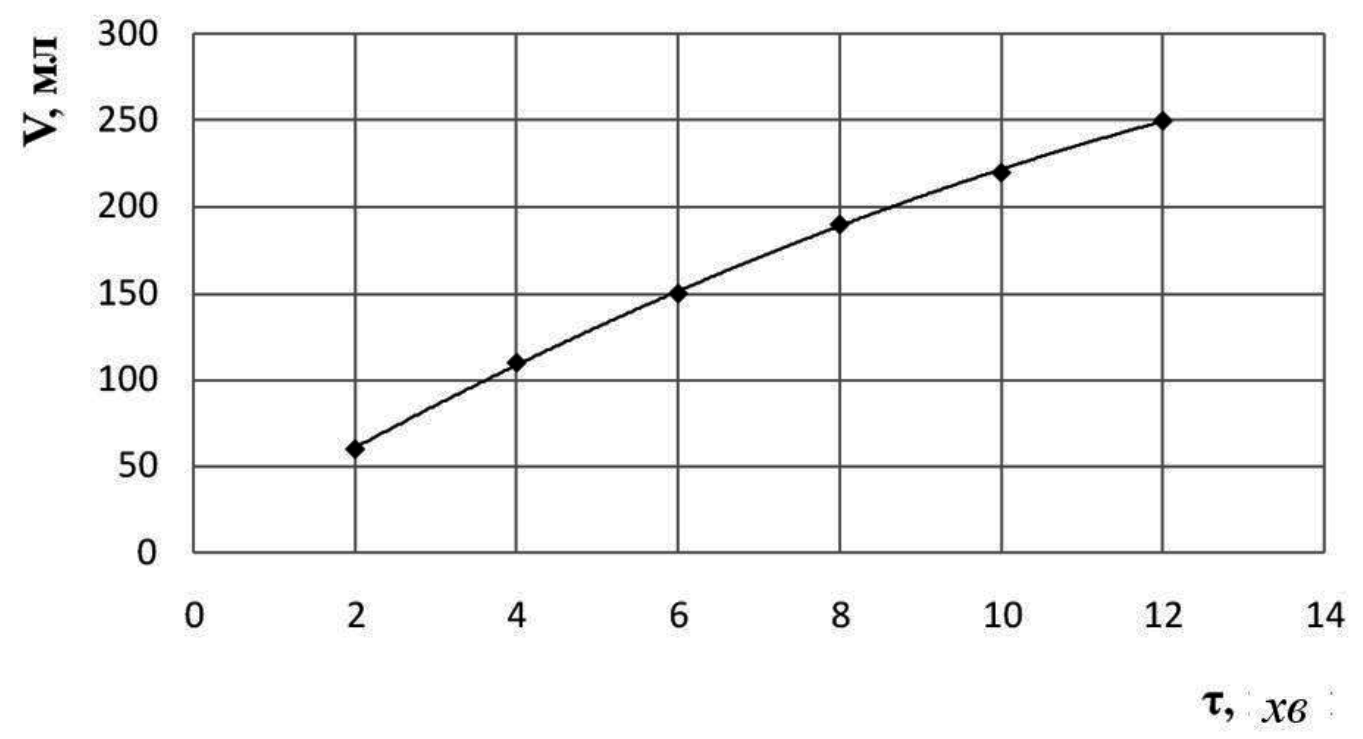

Рис. 3. Продуктивність установки по випареній волозі, мл/хв.

Виходячи 3 даних, які були підтверджені математичним моделюванням i експериментальними дослідженнями, приймаємо наступні вихідні параметри:

продуктивність, $G_{\text {вип.в. }}-1,5$ кг/год; температура теплоносія на вході в зону випарювання, $t_{m}^{\prime}$ $-80^{\circ} \mathrm{C}$;

температура теплоносія на виході з зони випарювання, $t_{m}^{\prime \prime} \quad-60^{\circ} \mathrm{C}$;

температура розчину в апараті, $t_{\kappa p}-35^{\circ} \mathrm{C}$;

температура культурального розчину, який подається на концентрування, $t_{\kappa p} \quad-15^{\circ} \mathrm{C}$.

Оскільки процес випарювання відбувається при температурі $80{ }^{\circ} \mathrm{C}$, значення необхідних для розрахунків величин при цій температурі для вуглекислого газу рівні: $\rho_{\mathrm{CO}_{2}}=1,97 \mathrm{\kappa} / \mathrm{M}^{3}$; $\mu_{\mathrm{CO}_{2}}=1716 \cdot 10^{-8} \Pi \mathrm{a} \cdot c ; \lambda_{\mathrm{CO}_{2}}=0,0204 \mathrm{BT} / \mathrm{M} \cdot K[3]$.

При температурі стінки $35{ }^{\circ} \mathrm{C}$, тобто в пристінному до дисків шарі вуглекислого газу, значення необхідних для розрахунків величин рівні: $\rho_{\mathrm{CO}_{2}}=1,97 \kappa \Gamma / \mathrm{M}^{3} ; \mu_{\mathrm{CO}_{2}}=1534 \cdot 10^{-8} \Pi \mathrm{Ta} \cdot c ; \lambda_{\mathrm{CO}_{2}}=$ $=0,0176 \mathrm{BT} / \mathrm{M} \cdot K[3]$.
Кількість тепла, яка необхідна для процесу концентрування[4]:

$Q_{\text {вип.в. }}=G_{\text {вип.в. }} \cdot r+G_{p} \cdot c \cdot \Delta t\left(\frac{\kappa Д ж}{\text { год }}\right)$,

де $Q_{\text {виn.в. }}-$ необхідна кількість тепла на концентрування;

$G_{\text {вип.в. }}$ - кількість випареної вологи в процесі концентрування, кг/год;

$r$ - питома теплота пароутворення при середній температурі, $r=2430$ кДж/кг;

$G_{p}$ - кількість розчину, яка передається на концентрування, $G_{p}=2,5$ кг/год;

$c$-теплоємність розчину, що концентрується, $c=$ $=3,927$ кДж/кг ${ }^{\circ} \mathrm{C}$;

$\Delta t$ - різниця температур розчину, що концентрується:

$\Delta t=t_{\kappa p}-t_{\kappa p}^{\prime}=35-15=20^{\circ} \mathrm{C}$.

Кількість випареної вологи змінюється від 1,1 до 1,5 л/год. в залежності від зміни швидкості теплоносія від 9,3 до 12,5 м/с, що в свою чергу змінює коефіцієнт тепловіддачі.

Тепломасообмінна поверхня однієї дискової насадки, при діаметрі $D=0,2$ м становить $f=$ $=0,0314 \mathrm{M}^{2}$. 
Реальна поверхня теплообміну при кількості $\alpha=Q_{\text {виn.в. }} / F \Delta t$. дискових насадок, зібраних в роторі $n=7$ шт, $F_{\text {реал }}=0,22 \mathrm{M}^{2}$.

Коефіцієнт тепловіддачі визначається за формулою:

Розраховані значення коефіцієнту тепловіддачі при різних швидкостях потоку теплоносія наведені на графіку (рис. 4).

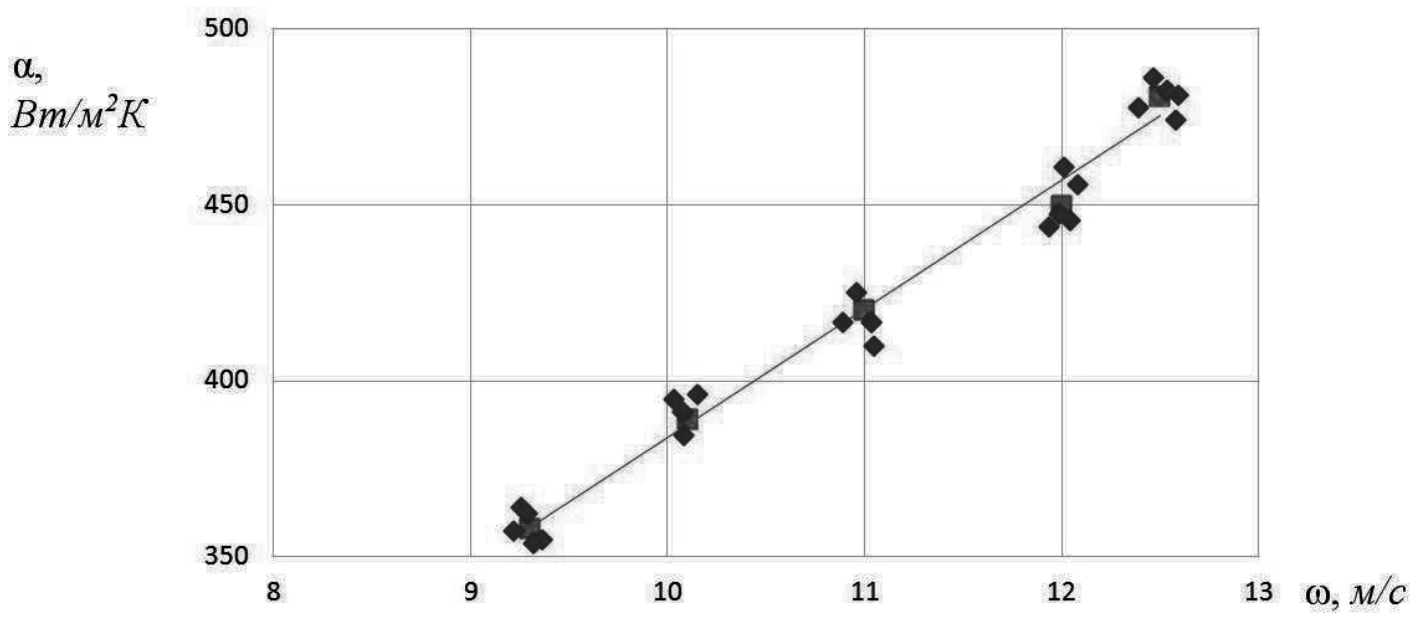

Рис. 4. Залежність коефіцієнта тепловіддачі від ивидкості потоку теплоносія.

Критерій Нуссельта:

$N u=\frac{\alpha_{n} d_{\ni}}{\lambda}$

Критерій Рейнольдса:

$\mathrm{Re}=\frac{\rho \omega_{n} d_{\ni}}{\mu}$, де $d_{\text {э }}$ - еквівалентний діаметр каналу для підведення теплоносія, $d_{\ni}=4 S / \Pi=0,06$ м.

Критерій Прандтля:

$\operatorname{Pr}=\frac{\mu c}{\lambda}$

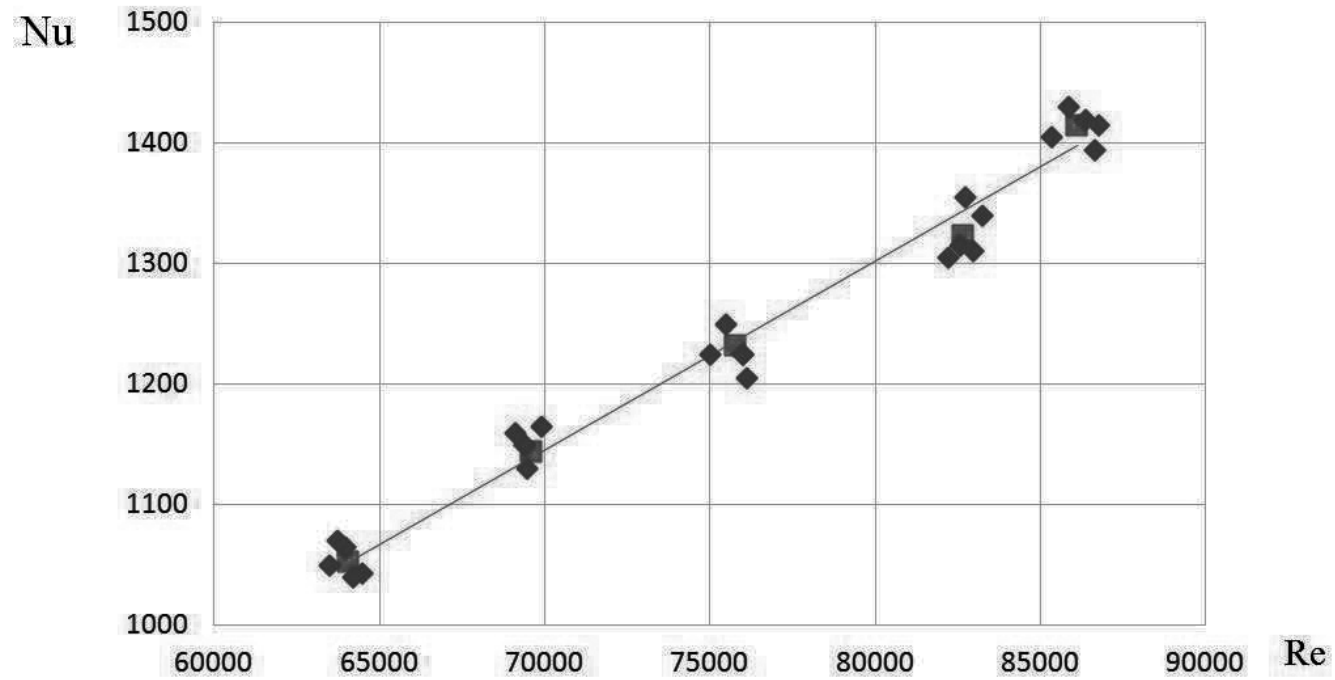

Рис. 5. Залежність експериментальних значень критерію Нусельта від числа Рейнольдса. 
Оскільки $\mathrm{Re}>10000$, то маємо турбулентний рух в каналі. Існує критеріальне рівняння тепловіддачі при турбулентному русі газу в тру-

$$
\begin{aligned}
& \text { бах }[4,5]: \\
& N u=0,021 \operatorname{Re}^{0,8} \operatorname{Pr}^{0,43}\left(\frac{\operatorname{Pr}}{\operatorname{Pr}_{c m}}\right)^{0,25} .
\end{aligned}
$$

Оскільки дані для розрахунку критерія Нуссельта за цим рівнянням відомі, проведемо дані розрахунки та визначимо за їх допомогою значення коефіцієнту тепловіддачі:

$\alpha_{n}=\frac{N u \lambda}{d_{\ni}}$.

Визначені таким чином коефіцієнти тепловіддачі в діапазоні швидкостей теплоносія 9,3...12,5 м/с наведені на рисунку 6 .

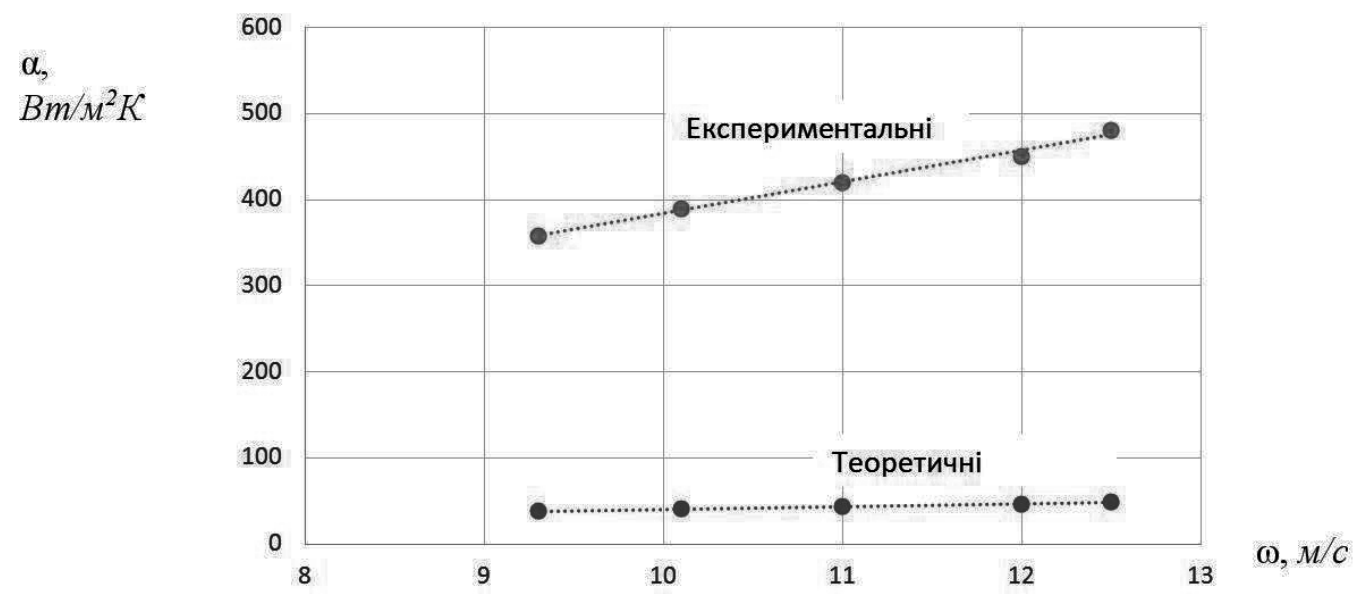

Рис. 6. Залежність коефіцієнта тепловіддачі від швидкості потоку теплоносія.

Виходячи 3 отриманих даних, можна зробити висновок, що дане критеріальне рівняння не адекватно описує процес тепловіддачі в РДПВА. Коефіцієнт $n$ критеріального рівняння Нуссельта відповідає за ступінь турбулізації потоку. Оскільки значення критерію Рейнольдса значно перевищує межу турбулентності було прийнято рішення про уточнення коефіцієнтів $C$ і $n$.
Модифіковане критеріальне рівняння набуває вигляду:

$$
N u=0,05 \operatorname{Re}^{0,91} \operatorname{Pr}^{0,43}\left(\frac{\operatorname{Pr}}{\operatorname{Pr}_{c m}}\right)^{0,25} .
$$

Дані, отримані при розрахунках коефіцієнту тепловіддачі за останнім рівнянням, зображені на рисунку 7.

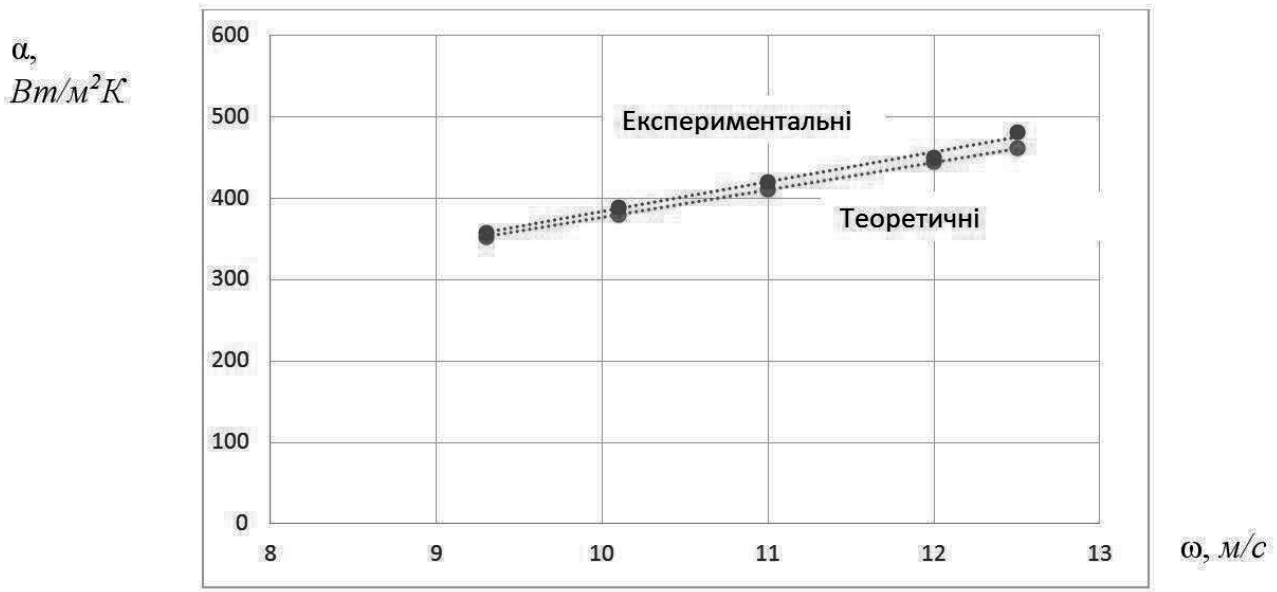

Рис. 7. Заленність коефіцієнта тепловіддачі від ивидкості потоку теплоносія, розраховані за модирікованим критеріальним рівнянням. 
Похибка між експериментальними та теоретичними значеннями складає менше $4 \%$, що $є$ достатньо хорошим показником.

\section{Висновки}

Експерименти показують, що в роторнодискових випарних апаратах для підвищення ефективності тепловіддачі, теплоносій доцільно подавати зі швидкістю від 9 до 12,5 м/с. Оскільки критеріальні рівняння для розрахунку коефіцієнтів тепловіддачі дисків, що повільно обертаються, відсутні, проведені експерименти дозволили встановити залежність між коефіцієнтом тепловіддачі $\alpha$ і подачі теплоносія в даному діапазоні швидкостей $\omega$.

Визначено уточнюючі коефіцієнти критеріального рівняння Нуссельта для вимушеної конвекції в каналі роторнодискового плівкового випарного апарату. Уточнюючі коефіцієнти, введені для конкретного апарату, підвищують точність інженерних розрахунків параметрів тепловіддачі та можуть бути використані при проектуванні тепломасообмінного обладнання для підвищення його ефективності роботи.

\section{ЛIТЕРАТУРА}

1. Костик С. И. Исследование технических и теплофизических характеристик универсального сушильного стенда по обезвоживанию термолабильных материалов/ С. И. Костик, А. Н. Ободович // Молодой ученый. - 2014. - №4. - С. 195198.

2. Ободович О. М. Розрахунок теплових та енергетичних потоків роторно-дискового випарного апарата для зневоднення термолабільних матеріалів/ О. М. Ободович, С. І. Костик // Международный научно-производственный журнал «Керамика: наука и жизнь» - 2014, 2/23 - С.4-13.

3. Варгафтик Н. Б. Справочник по теплофизическим свойствам газов и жидкостей / Н.Б. Варгафтик. - М.: Наука, 1972. - 720 с.

4. Лебедев П. Д. Расчет и проектирование сушильных установок / П. Д. Лебедев // М.- Л.: Госэнергоиздат, 1963. - 320 с.

5. Уонг X. Основные формулы и данные по теплообмену для инженеров / Х. Уонг - М.: Атомиздат, 1979. $-216 \mathrm{c}$.

6. Бухмиров В. В. Расчет коэффициента конвективной теплоотдачи (основные критериальные уравнения) / В. В. Бухмиров // Иваново: Государственный энергетический университет, 2007. -39 c. 


\section{FEATURES OF HEAT FORCED CONVECTION IN A ROTOR-DISC FILM EVAPORATOR}

Obodovich A.N. ${ }^{1}$, Ruzhinskaya L.I. ${ }^{2}$, Kostyk S.I. ${ }^{1},{ }^{2}$

${ }^{1}$ Institute of Engineering Thermophysics of the National Academy of Sciences of Ukraine, vul. Zhelyabova, 2a, Kyiv, 03680, Ukraine

${ }^{2}$ National Technical University of Ukraine "KPI", ave. Pobedu, 37, building 4, Kyiv, 03056, Ukraine

Heat emission factors from carbonic acid gas to liquid for gas speed about $9,3 \ldots 12,5 \mathrm{~m} / \mathrm{s}$ in the rotary-disk tape evaporative apparatus canal.

The modified criterion equation of heat transfer in forced convection rotary disc film evaporator, which can be used to improve the accuracy of engineering calculations of heat and mass transfer parameters of heat transfer equipment.

Key words: heat transfer, forced convection, rotarydisc film evaporator, heat and mass transfer.
1. Kostik S. I. Investigation of the technical characteristics and thermal drying universal stand by dehydration termolabile materials / S.I. Kostik, A.N. Obodovich // Young scientist. - 2014. - №4. P. 195-198. (Rus.)

2. Obodovich O. M. Calculation of heat and energy flows of disk rotor-evaporator for dehydration thermally labile materials / O. M. Obodovich, S. I. Kostik // International scientific journal "Ceramics: Science and Life" - 2014, 2/23 - P.4 - 13. (Ukr.)

3. Vargaftik N. B. Handbook on thermophysical properties of gases and liquids / N.B. Vargaftik // M.: Nauka, 1972. - 720 p. (Rus.)

4. Lebedev P. D. Calculation and designing of dryers / P. D. Lebedev // M.- L.: Gosenergoizdat, 1963. -320 p. (Rus.)

5. Uong $H$. The basic formulas and data on heat transfer for engineers / H. Uong - M.: Atomizdat, 1979. - 216 p. (Rus.)

6. Buhmirov $V$. $V$. Calculation of the convective heat transfer (basic criteria equations) / V. V. Buhmirov // Ivanovo: State Power University, 2007. -39 p. (Rus.) 